\section{Cureus}

Received 08/30/2014

Review began 08/31/2014

Review ended 09/10/2014

Published 09/12/2014

\section{(C) Copyright 2014}

Awad et al. This is an open access article distributed under the terms of the Creative Commons Attribution License CC-BY 3.0., which permits unrestricted use, distribution, and reproduction in any medium, provided the original author and source are credited.

\title{
The Use of 5-ALA in Glioblastoma Resection: Two Cases with Long-Term Progression-Free Survival
}

\author{
Ahmed J. Awad ${ }^{1}$, Andrew Sloan ${ }^{2}$ \\ 1. Faculty of Medicine and Health Sciences, An-Najah National University, Nablus, Palestine 2. \\ University Hospital Case Medical Center
}

$\square$ Corresponding author: Ahmed J. Awad,dr_ahmedja@hotmail.com Disclosures can be found in Additional Information at the end of the article

\section{Abstract}

Glioblastoma is the most common and most lethal of all primary brain tumors. Even with the standard triad of surgery, chemotherapy, and radiation therapy, life expectancy is still poor, with a median survival less than 15 months following initial diagnosis. Even though the extent of surgical resection is a prognostic factor affecting outcome, most surgical studies have noted that the complete resection rates are poor due to difficulty in defining the tumor margin intraoperatively. Fluorescence-guided resection (FGR) helps to visualize tumor cells, allowing more complete resection. 5-aminolevulinic acid (5-ALA) in glioma resection has been widely used around the world; however, it is has not been approved in the United States. In this paper, we report two cases of long-term progression-free survival in patients with glioblastoma surgically resected using of 5-ALA.

Categories: Miscellaneous, Neurosurgery

Keywords: aminolevulinic acid, fluorescence imaging, glioma, brain tumor, neuro-oncology

\section{Introduction}

Glioblastoma (GBM) is the most aggressive primary brain tumor in adults as well as the most common glioma comprising $12 \%-20 \%$ of all brain tumors. The incidence rate of GBM in the United States is estimated to be 2.69 per 100,000 persons per year [1-2]. Even with the standard triad of surgery, chemotherapy, and radiation therapy, life expectancy is still poor, with a median survival of less than 15 months following initial diagnosis [3].

The most important prognostic factors affecting survival in patients with GBM are age, tumor grade, performance score, molecular mutations, and the extent of surgical resection (EOR). However, surgical studies have noted that complete resection is achieved in less than half of all patients due to difficulties in determining tumor margins intraoperatively [4-5]. Hence, there is an urgent need for novel technologies to increase the extent of surgical resection. One such strategy includes fluorescence-guided resection (FGR) for more complete tumor resection.

In this paper, we report two cases of long-term progression-free survival in patients with glioblastoma undergoing FGR using of 5-aminolevulinic acid (5-ALA-FGR) at the University Hospitals-Case Medical Center.

\section{Case Presentation}

Informed patient consent was obtained from the patients discussed in this paper. No 


\section{Cureus}

identifying patient data was used. The University Hospitals-Case Medical Center Review Board issued approval (protocol \#1305).

\section{Case 1}

A 44-year-old, left-handed female with a right parietal GBM was admitted to our center for surgical resection. Preoperative magnetic resonance imaging (MRI) demonstrated enhancing tumor just behind primary motor cortex (Figure 1). The patient underwent surgical resection using motor mapping and 5-ALA. 5-ALA demonstrated infiltrating tumor outside the tumor margin (Figure 2) indicated by T1 weighted gadolinium (Gd) enhancement enabling complete resection as confirmed by intraoperative MRI (iMRI) (Figure 3).

Patient was intact postoperatively with complete resection that recurred only after 23 months. She had invasion across the corpus callosum at recurrence and was not considered to be a surgical candidate. She was treated with avastin (bevacizumab) and survived 28.5 months postrecurrence. The overall survival was 51.5 months since first surgical resection.

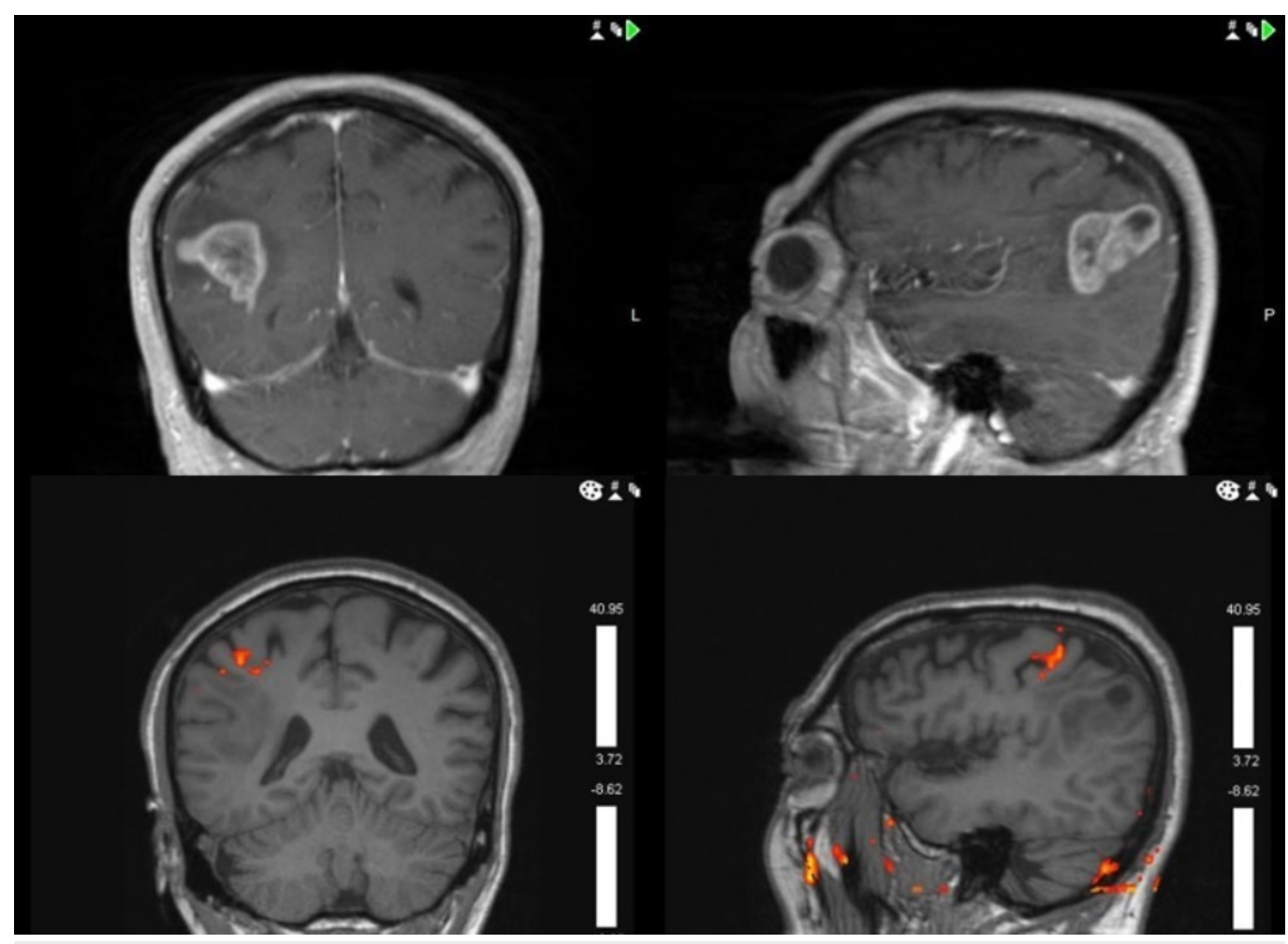

FIGURE 1: Preoperative magnetic resonance imaging (MRI) showing enhancing tumor just behind primary motor cortex in the right parietal lobe. 


\section{Cureus}

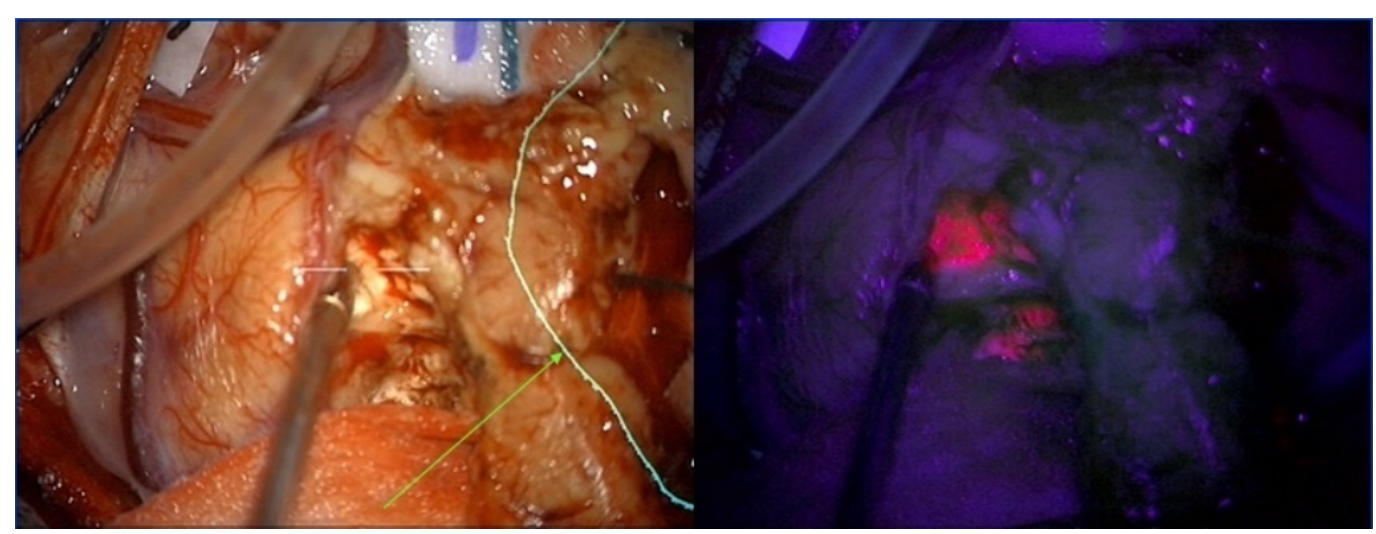

FIGURE 2: 5-ALA showing infiltrating tumor outside the presumed tumor margin (arrow)

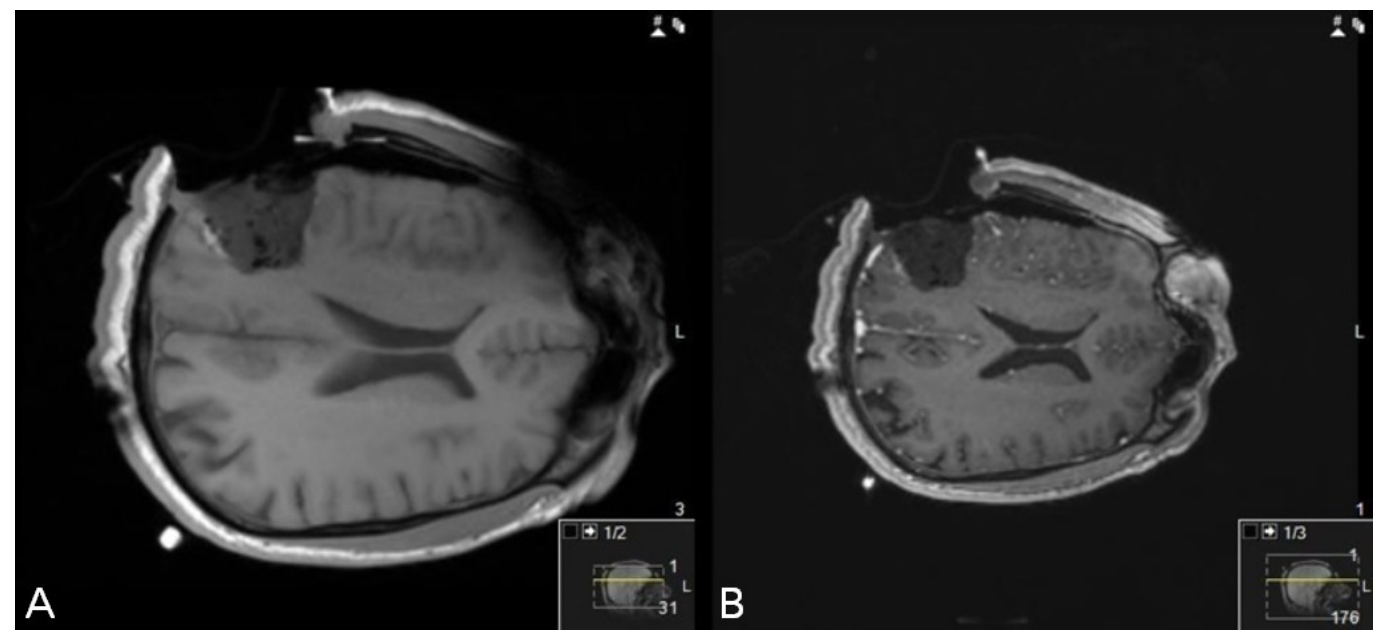

FIGURE 3: Intra-operative MRI (iMRI) non-contrast (A) and gadolinium contrast $(B)$ images confirm gross total resection

\section{Case 2}

A 63-year-old, right-handed female presented to outside hospital with seizures and found to have GBM in left parietal lobe. She underwent surgery at an outside hospital but only 10\% was resected (Figure 4). Her radiation oncologist referred the patient for completion surgery. 5-ALA demonstrated a solid mass infiltrating the edematous brain along the margin (Figure 5).

The patient underwent 5-ALA-FGR and postoperative MRI demonstrated complete resection with preservation of feeding vessels (Figure 6). She subsequently was treated using the standard therapy [3] and currently is intact with a progression-free survival of 23 months. 


\section{Cureus}

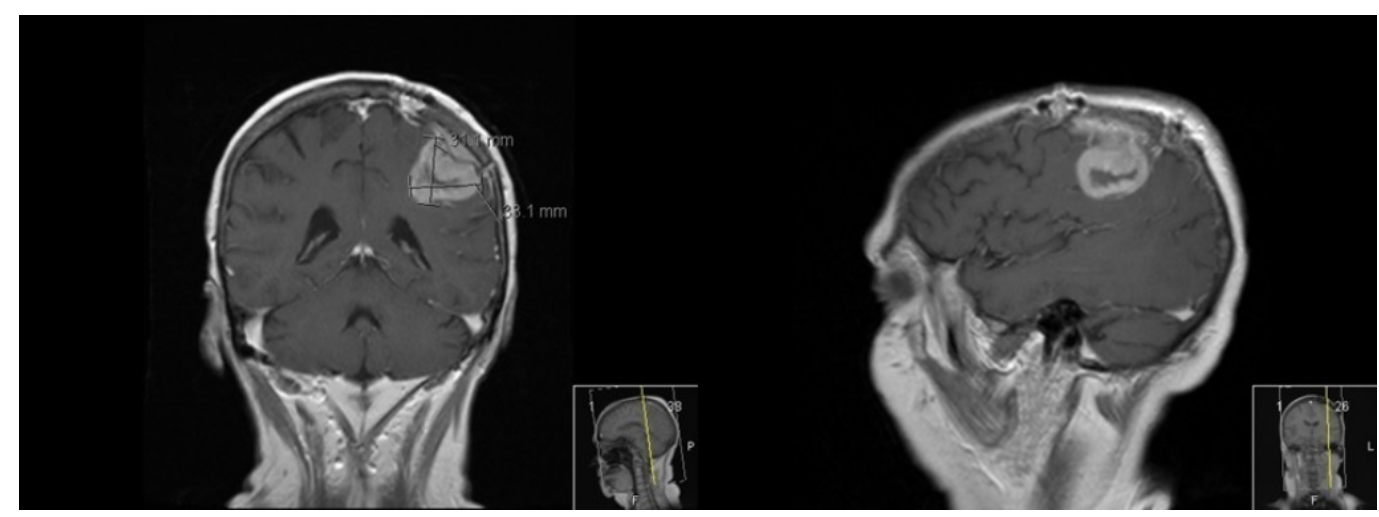

FIGURE 4: Preoperative magnetic resonance imaging (MRI) showing that only $10 \%$ of the tumor was resected in the first surgery.

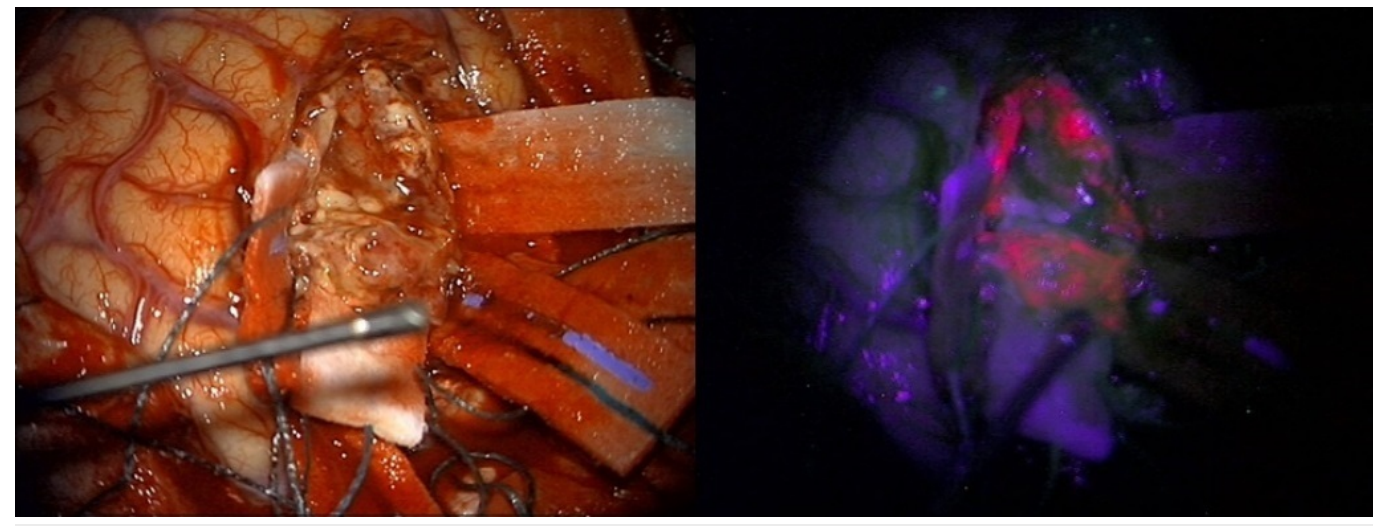

FIGURE 5: 5-ALA showing solid tumor infiltrating to edematous brain

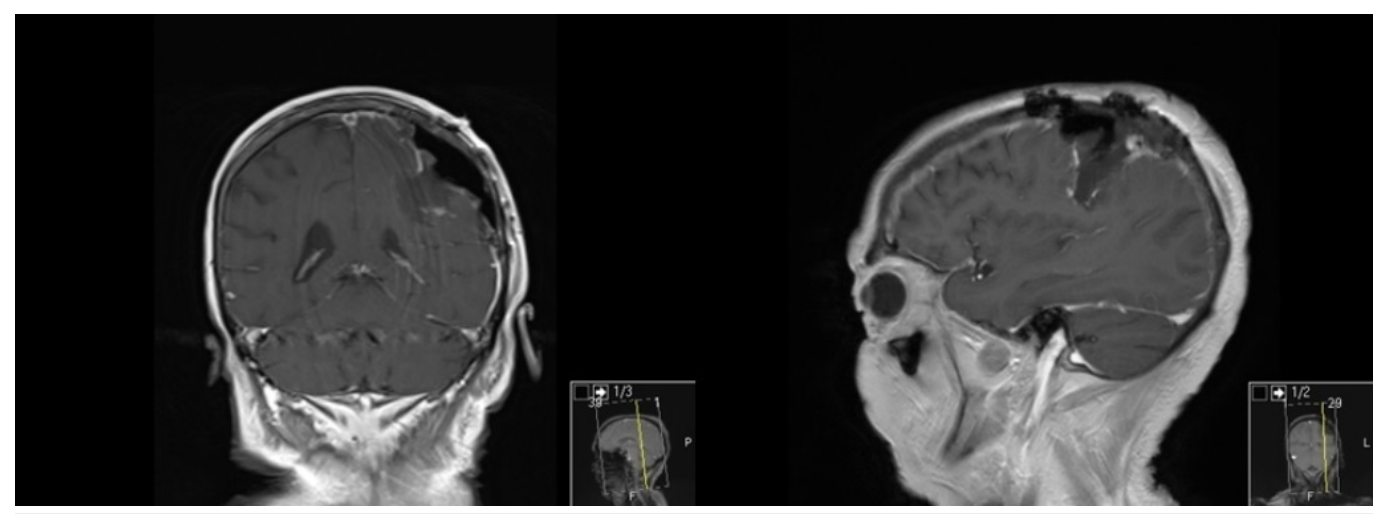

FIGURE 6: Postoperative MRI demonstrating complete 


\section{Discussion}

Glioblastoma is the most common and most lethal of all primary brain tumors. The standard treatment for GBM changed in 2005 following the results of a Phase III trial of temozolomide for newly diagnosed glioblastoma [3]. The triad of surgery, temozolomide (TMZ), and radiation therapy (RT), also known as Stupp regimen, demonstrated a median survival of 14.6 months [3]. However, Johnson and O'Neill have recently analyzed the survival time of all adult patients with GBM in the United States during the TMZ era [6]. Based on Data from the Surveillance, Epidemiology, and End Results (SEER), the authors found that median survival times of all patients with newly diagnosed glioblastoma was only 9.7 months in 2005-2008 (during the TMZ era) [6]. Hence, there was an urge to discover new technologies and treatment strategies to extend survivals in GBM patients.

5-aminolevulinic acid is the first compound in the hemoglobin synthesis pathway. It is formed within the mitochondria from glycine and succinyl-coenzyme A by 5-ALA-synthetase. 5-ALA elicits synthesis and accumulation of fluorescent porphyrins in epithelia and neoplastic tissues, including glioblastoma [7]. Moreover, several studies demonstrated that malignant cells accumulate more 5-ALA than healthy cells [8-10]. The recommended dose of 5-ALA is $20 \mathrm{mg} / \mathrm{kg}$ body weight. The patient takes an oral dose of 5-ALA three to four hours prior to surgery. Once craniotomy is performed, the neurosurgeon switches between using conventional white light and a violet-blue filter which leads to fluorescence of a deep pink glow in tumor cells which have taken up 5-ALA. This allows the tumor cells to be differentiated from the healthy tissue allowing more complete resection.

The introduction of 5-ALA-FGR [11], followed by the successful results of the Phase III trial, is representative of major advances in glioblastoma therapy in the past years [12]. The ALAGlioma Study Group, led by Stummer, performed a randomized control trial comparing patients who underwent surgical resection using 5-ALA-FGR versus conventional white light and found that patients in the FGR group had higher six month progression-free survival [12]. Moreover, several studies demonstrated that more extensive surgical resection is associated with longer life expectancy for GBMs [5, 13-14]. Specifically, if 78\% of the tumor can be resected, this significantly extends the survival time, and incremental improvement in survival in the $95 \%$ to $100 \%$ extent of resection [14]. Díez Valle, et al. [15] assessed the EOR in patients undergoing 5-ALA-FGR. They found that all patients had resection over $98 \%$ of the volume and mean volume resected was $99.8 \%$.

Preoperative T1 MRI with gadolinium contrast is useful in determining the location of the tumor prior to surgery. Aldave and colleagues found that patients who underwent 5-ALA-FGR beyond what was seen on contrast-enhancing MRIs had longer overall survival compared with patients with residual fluorescent tissue [16]. Moreover, Coburger, et al. [17] have recently demonstrated that 5-ALA is superior to Gd-DTPA-enhanced iMRI for detection of infiltrating tumor at the border of the resection cavity. These studies indicate that resections beyond the 5ALA-positive tissue can prolong survival in GBM patients.

Nonetheless, there are also several limitations of 5-ALA-FGR for GBM resection. 5-ALA specificity tends to be lower in areas of vague fluorescence at tumor margins [18]. Additionally, 5-ALA fluorescence only occurs when the molecules are hit by a blue light of approximately 440 $\mathrm{nm}$; therefore, active tumor can be hidden by overhanging normal tissues which lie between the tumor and the microscope, blood, hematoma, or necrotic tissues typically seen in GBM resulting in less than complete resections. Moreover, 5-ALA may interfere with other drugs, 
such as phenytoin [19]. For this reason, and because MRI is widely considered to be the goldstandard for determining EOR, combining 5-ALA-FGR with iMRI, as in Case 1, may yield improved EOR compared to either technology alone [20]. 5-ALA is also associated with a few side-effects, including hypotension, elevated liver enzymes and mild photosensitivity [21-22].

5-ALA in glioma resection has been widely used around the world for more complete tumor resections. Unfortunately, the Food and Drug Administration (FDA) has not yet approved the use of 5-ALA in the United States. FDA considers 5-ALA a drug, rather than a surgical aid, which would require a lengthy process. Currently, there are several 5-ALA clinical trials in the United States that will hopefully lead to FDA approval of oral 5-ALA for intra-operative visualization of glioblastoma.

\section{Conclusions}

These two case reports illustrate the advantage of 5-ALA in achieving more complete resection, as confirmed by iMRI, and long-term progression-free survival in GBM patients. 5-ALA is a relatively safe and inexpensive surgical aid. In some cases, 5-ALA has been reported to be equally effective and sometimes more effective than MRI technology, though they appear to be complementary. Thus, the combination of both 5-ALA and iMRI might be beneficial to maximize the extent of resection.

\section{Additional Information Disclosures}

Human subjects: Consent was obtained by all participants in this study. University HospitalsCase Medical Center issued approval IRB protocol \#1305. Conflicts of interest: In compliance with the ICMJE uniform disclosure form, all authors declare the following: Payment/services info: All authors have declared that no financial support was received from any organization for the submitted work. Financial relationships: All authors have declared that they have no financial relationships at present or within the previous three years with any organizations that might have an interest in the submitted work. Other relationships: All authors have declared that there are no other relationships or activities that could appear to have influenced the submitted work.

\section{References}

1. Ostrom QT, Gittleman H, Farah P, Ondracek A, Chen Y, Wolinsky Y, Stroup NE, Kruchko C, Barnholtz-Sloan JS: CBTRUS statistical report: Primary brain and central nervous system tumors diagnosed in the United States in 2006-2010. Neuro Oncol. 2013, 15:ii1-56. 10.1093/neuonc/not151

2. Fuller GN: Brain Tumors: An Overview of Current Histopathologic Classifications. Youmans Neurological Surgery. Youmans JR (ed): Elsevier/Saunders, Philadelphia, PA; 2011. 1077-1086.

3. Stupp R, Mason WP, van den Bent MJ, Weller M, Fisher B, Taphoorn MJ, Belanger K, Brandes AA, Marosi C, Bogdahn U, Curschmann J, Janzer RC, Ludwin SK, Gorlia T, Allgeier A, Lacombe D, Cairncross JG, Eisenhauer E, Mirimanoff RO; European Organisation for Research and Treatment of Cancer Brain Tumor and Radiotherapy Groups; National Cancer Institute of Canada Clinical Trials Group: Radiotherapy plus concomitant and adjuvant temozolomide for glioblastoma. N Engl J Med. 2005, 352:987-96.

4. Vecht CJ, Avezaat CJ, van Putten WL, Eijkenboom WM, Stefanko SZ: The influence of the extent of surgery on the neurological function and survival in malignant glioma. A retrospective analysis in 243 patients. J Neurol Neurosurg Psychiatry. 1990, 53:466-71.

5. Albert FK, Forsting M, Sartor K, Adams HP, Kunze S: Early postoperative magnetic resonance imaging after resection of malignant glioma: Objective evaluation of residual tumor and its influence on regrowth and prognosis. Neurosurg. 1994, 34:45-60.

6. Johnson DR, O'Neill BP: Glioblastoma survival in the United States before and during the 
temozolomide era. J Neurooncol. 2012, 107:359-64. 10.1007/s11060-011-0749-4

7. Regula J, MacRobert AJ, Gorchein A, Buonaccorsi GA, Thorpe SM, Spencer GM, Hatfield AR, Bown SG: Photosensitisation and photodynamic therapy of oesophageal, duodenal, and colorectal tumours using 5 aminolaevulinic acid induced protoporphyrin IX--a pilot study. Gut. 1995, 36:67-75.

8. Peng Q, Berg K, Moan J, Kongshaug M, Nesland JM: 5-Aminolevulinic acid-based photodynamic therapy: principles and experimental research. Photochem Photobiol. 1997, 65:235-51.

9. Wyss-Desserich MT, Sun CH, Wyss P, Kurlawalla CS, Haller U, Berns MW, Tadir Y: Accumulation of 5-aminolevulinic acid-induced protoporphyrin IX in normal and neoplastic human endometrial epithelial cells. Biochem Biophys Res Commun. 1996, 224:819-24.

10. Campbell DL Gudgin-Dickson EF, Forkert PG, Pottier RH, Kennedy JC: Detection of early stages of carcinogenesis in adenomas of murine lung by 5 -aminolevulinic acid-induced protoporphyrin IX fluorescence. Photochem Photobiol. 1996, 64:676-82.

11. Stummer W, Novotny A, Stepp H, Goetz C, Bise K, Reulen HJ: Fluorescence-guided resection of glioblastoma multiforme by using 5 -aminolevulinic acid-induced porphyrins: a prospective study in 52 consecutive patients. J Neurosurg. 2000, 93:1003-13.

12. Stummer W, Pichlmeier U, Meinel T, Wiestler OD, Zanella F, Reulen HJ; ALA-Glioma Study Group: Fluorescence-guided surgery with 5-aminolevulinic acid for resection of malignant glioma: a randomised controlled multicentre phase III trial. Lancet Oncol. 2006, 7:392-401.

13. Lacroix M, Abi-Said D, Fourney DR, Gokaslan ZL, Shi W, DeMonte F, Lang FF, McCutcheon IE, Hassenbusch SJ, Holland E, Hess K, Michael C, Miller D, Sawaya R: A multivariate analysis of 416 patients with glioblastoma multiforme: prognosis, extent of resection, and survival. J Neurosurg. 2001, 95:190-198.

14. Sanai N, Polley MY, McDermott MW, Parsa AT, Berger MS: An extent of resection threshold for newly diagnosed glioblastomas. J Neurosurg. 2011, 115:3-8. 10.3171/2011.2.JNS10998

15. Díez Valle R, Tejada Solis S, Idoate Gastearena MA, García de Eulate R, Domínguez Echávarri $\mathrm{P}$, Aristu Mendiroz J: Surgery guided by 5-aminolevulinic fluorescence in glioblastoma: volumetric analysis of extent of resection in single-center experience. J Neurooncol. 2011, 102:105-13. 10.1007/s11060-010-0296-4

16. Aldave G, Tejada S, Pay E, Marigil M, Bejarano B, Idoate MA, Díez-Valle R: Prognostic value of residual fluorescent tissue in glioblastoma patients after gross total resection in 5aminolevulinic Acid-guided surgery. Neurosurg. 2013, 72:915-20. 10.1227/NEU.0b013e31828c3974

17. Coburger J, Engelke J, Scheuerle A, Thal DR, Hlavac M, Wirtz CR, König R: Tumor detection with 5-aminolevulinic acid fluorescence and Gd-DTPA-enhanced intraoperative MRI at the border of contrast-enhancing lesions: a prospective study based on histopathological assessment. Neurosurg Focus. 2014, 36:E3. 10.3171/2013.11.FOCUS13463

18. Li Y, Rey-Dios R, Roberts DW, Valdés PA, Cohen-Gadol AA: Intraoperative fluorescenceguided resection of high-grade gliomas: A Comparison of the present techniques and evolution of future strategies. World Neurosurg. 2014, 82:175-185.

10.1016/j.wneu.2013.06.014

19. Hefti M, Albert I, Luginbuehl V: Phenytoin reduces 5-aminolevulinic acid-induced protoporphyrin IX accumulation in malignant glioma cells. J Neurooncol. 2012, 108:443-50. 10.1007/s11060-012-0857-9

20. Eyüpoglu IY, Hore N, Savaskan NE, Grummich P, Roessler K, Buchfelder M, Ganslandt O: Improving the extent of malignant glioma resection by dual intraoperative visualization approach. PLoS One. 2012, 7 :e44885. 10.1371/journal.pone.0044885

21. Webber J, Kessel D, Fromm D: Side effects and photosensitization of human tissues after aminolevulinic acid. J Surg Res. 1997, 68:31-7.

22. Chung IW, Eljamel S: Risk factors for developing oral 5-aminolevulinic acid-induced side effects in patients undergoing fluorescence guided resection. Photodiagnosis Photodyn Ther. 2013, 10:362-7. 10.1016/j.pdpdt.2013.03.007 